
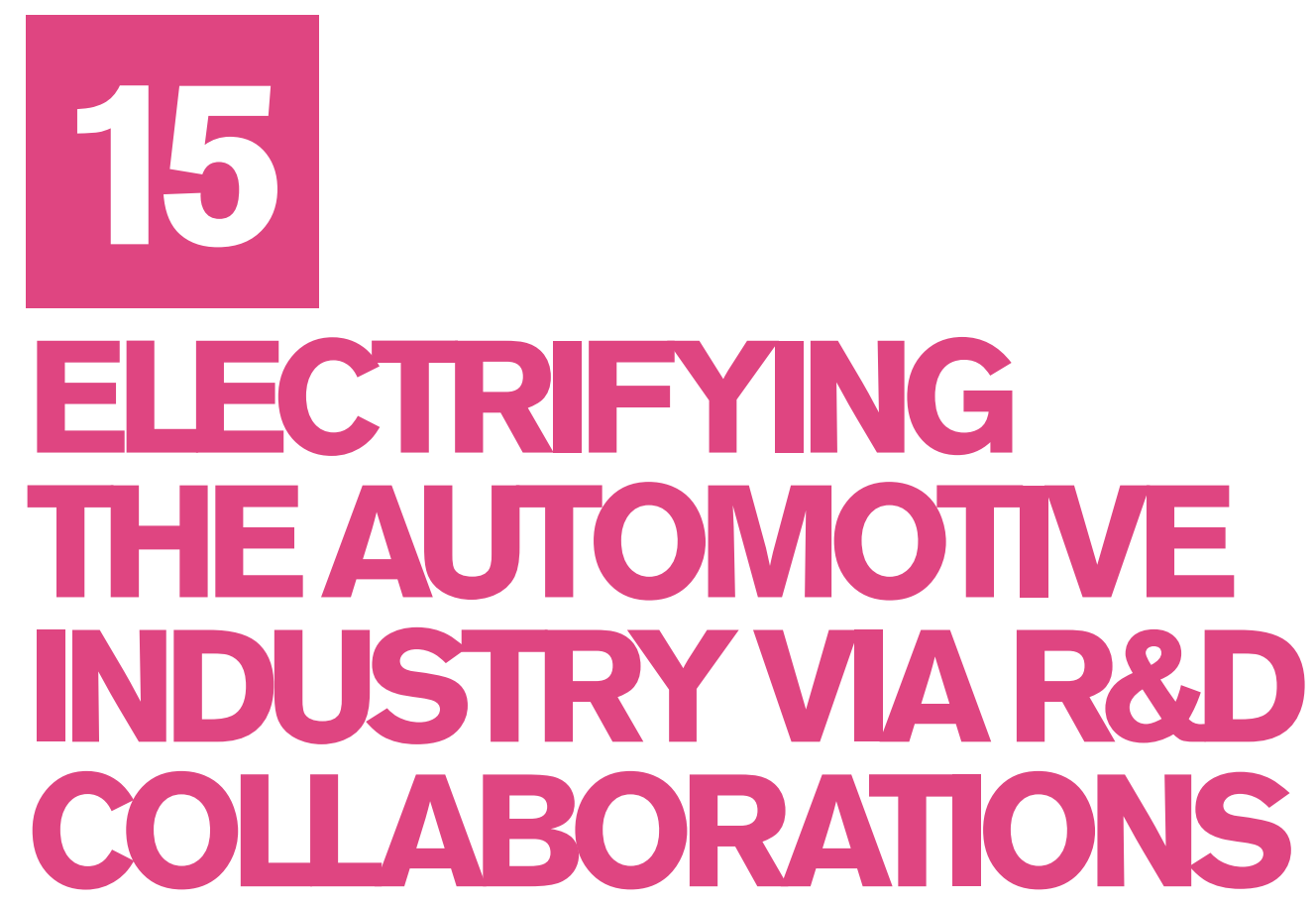

Steven Sarasini

Björn Sandén

Department of Energy and Environment, Chalmers University of Technology*

\title{
Magnus Karlström
}

Chalmers Industriteknik

* Division of Environmental Systems Analysis

Chapter reviewer: Niklas Thulin, Volvo Technology

\section{INTRODUCTION}

The electrification of vehicles has regained popularity in the last two decades. Staying abreast of the electromobility trend poses challenges for automakers. One challenge is that electrification requires knowledge and competences that are different from those associated with the internal combustion engines (ICE). ${ }^{1}$ Integrating components such as electric motors, batteries and regenerative braking systems, for instance, requires that automakers develop more complex systems to control and monitor electrical subsystems and components (see Chapters $\underline{3}$ and 4). Such developments require automakers to further develop competences in fields such as electronics and computing. Connecting electric vehicles to the electricity grid requires developments in ICT and utilises competences from electric power engineering, often in collaboration with utility companies (see Chapter 9). Specifically, electromobility means that automakers must integrate three competences areas that are sometimes described as 'me-chem-tronics' (mechani$\mathrm{cal}$, chemical and electronic competences), alongside raw material management. ${ }^{2}$ Overall the transition to electromobility means that automakers must increasingly draw on skills and knowhow that are beyond their traditional competence bases (see Chapter 2).

1 Aggeri F, Elmquist, M. and Pohl, H. (2009). Managing learning in the automotive industry - the innovation race for electric vehicles. International Journal of Automotive Technology and Management Vol. 9 No. 2, pp. 123-147.

2 Frick et al. (2011). Boost! Transforming the powertrain value chain - a portfolio challenge. McKinsey. 
Automakers may thus find it useful to seek out external partners with competences and knowledge that can assist in the electromobility transition. The strategic alliance between Renault and Nissan, for instance, aims in part to develop 'zeroemission' transportation ${ }^{3}$ their most notable achievement hitherto being the Nissan Leaf battery electric vehicle. In practice the alliance allows Renault access to Nissan's joint venture activities such as the Automotive Energy Supply Corporation, whose aim is the development and mass-production of lithium-ion batteries. The alliance is one example of a network strategy designed to help develop and access new and existing knowledge relevant for innovation and which can boost competitive advantage.

This chapter presents some findings of a recent study that examined the structure of collaborative knowledge networks in the automotive industry. ${ }^{4}$ In particular, the study utilised quantitative methods based on the analysis of bibliometric and patent data to examine 1) how automakers have collaborated with external partners in terms of their traditional lines of research and development and 2) how automakers and suppliers to the automotive industry collaborate in terms of R\&D that is useful for electrification. Whilst quantitative methods produced relatively comprehensive and concrete findings, the conclusions presented here are limited by the fact that qualitative methods based on interviews, for instance, would provide a much more nuanced understanding of the way automakers collaborate on R\&D activities. Our conclusions are thus tentative and intended to form the basis for future research in R\&D collaboration.

\section{R\&D ACTIVITIES IN THE ELECTROMOBILITY FIELD}

The recent upsurge in attention for electromobility is reflected in an exponential increase in the number of scientific journal publications focusing on electric and hybrid electric vehicles from the beginning of the 1990s to the present day (Figure 15.1)

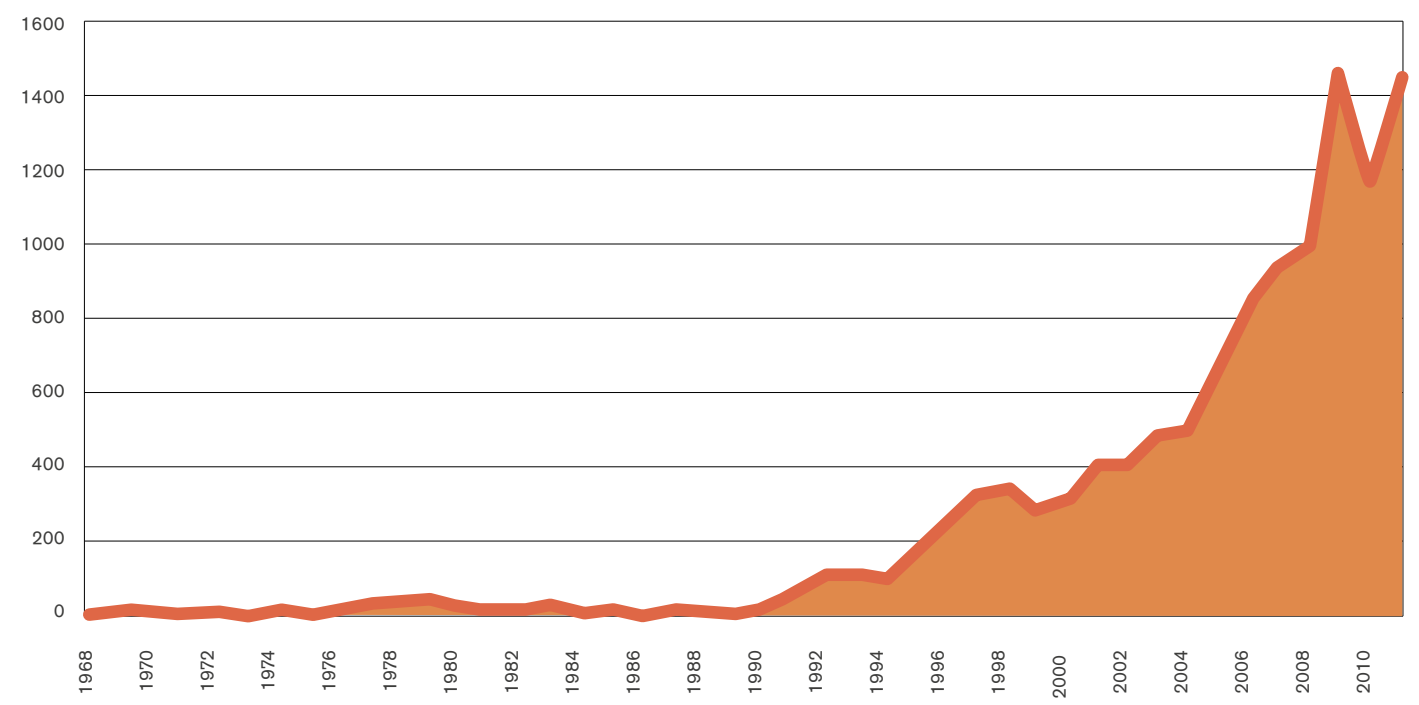

Figure 15.1 Numbers of scientific journal publications on electric and hybrid electric vehicles 1968-2012.

3 See Nissan Zero Emission Website - Partnership. Accessed on October 1, 2012.

4 Sarasini, S. Electrifying the automotive industry: Networks of R\&D collaboration. Under review by Environmental Innovation and Societal Transitions. 
However, the development of technological knowledge and competences for electrification may be somewhat unevenly dispersed across the globe, with some companies, countries and regions having performed more R\&D than others. This is perhaps because countries with strengths in the automotive industry spend varying amounts on R\&D for electrification and prioritise different areas. Government R\&D funding in Sweden, for instance, has previously prioritised hybrid powertrains and control systems for vehicles, but in the first years after the turn of the century funding for research on batteries, fuel cells and hydrogen infrastructure was lacklustre in comparison to Japan and the USA (Arnold et al., 2007). Bibliometric data suggests that the USA, China and Japan are the most active on electrification R\&D (in absolute terms) and that technical colleges universities that focus on engineering sciences and which are located close to automobile manufacturers boast the greatest number of publications (Figure 15.2).

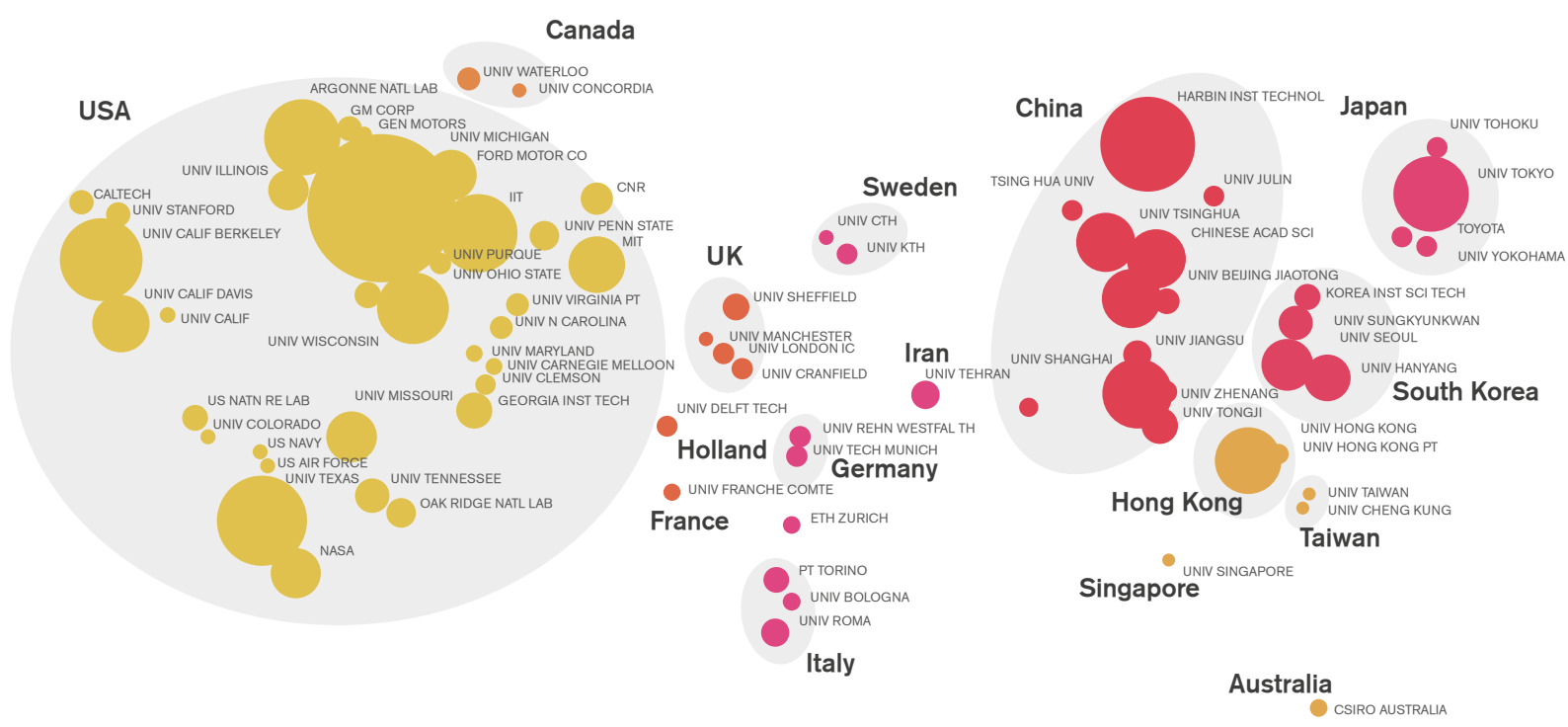

Figure 15.2 Scientific journal publications on electric and hybrid electric vehicles per institution (Only organisations with at least 100 publications from 1968 to 2012 are included.)

Furthermore, countries appear to be variously willing to transform research efforts into innovations, as Japanese companies own more patents associated with electrification compared to companies located elsewhere (Figure 15.3).

Taken together, the data presented here suggest that China, the US and Japan are the most active in terms of R\&D in the electrification field. However Table 15.1 shows that, in 2002, Japanese and US-based firms owned the majority of "significant" patents in the field of electrification. ${ }^{5}$ China may have emerged as a key player since 2002, and its role is expected to grow in years to come. In 2009, the Chinese government outlined plans to become the global market leader. ${ }^{6}$ 


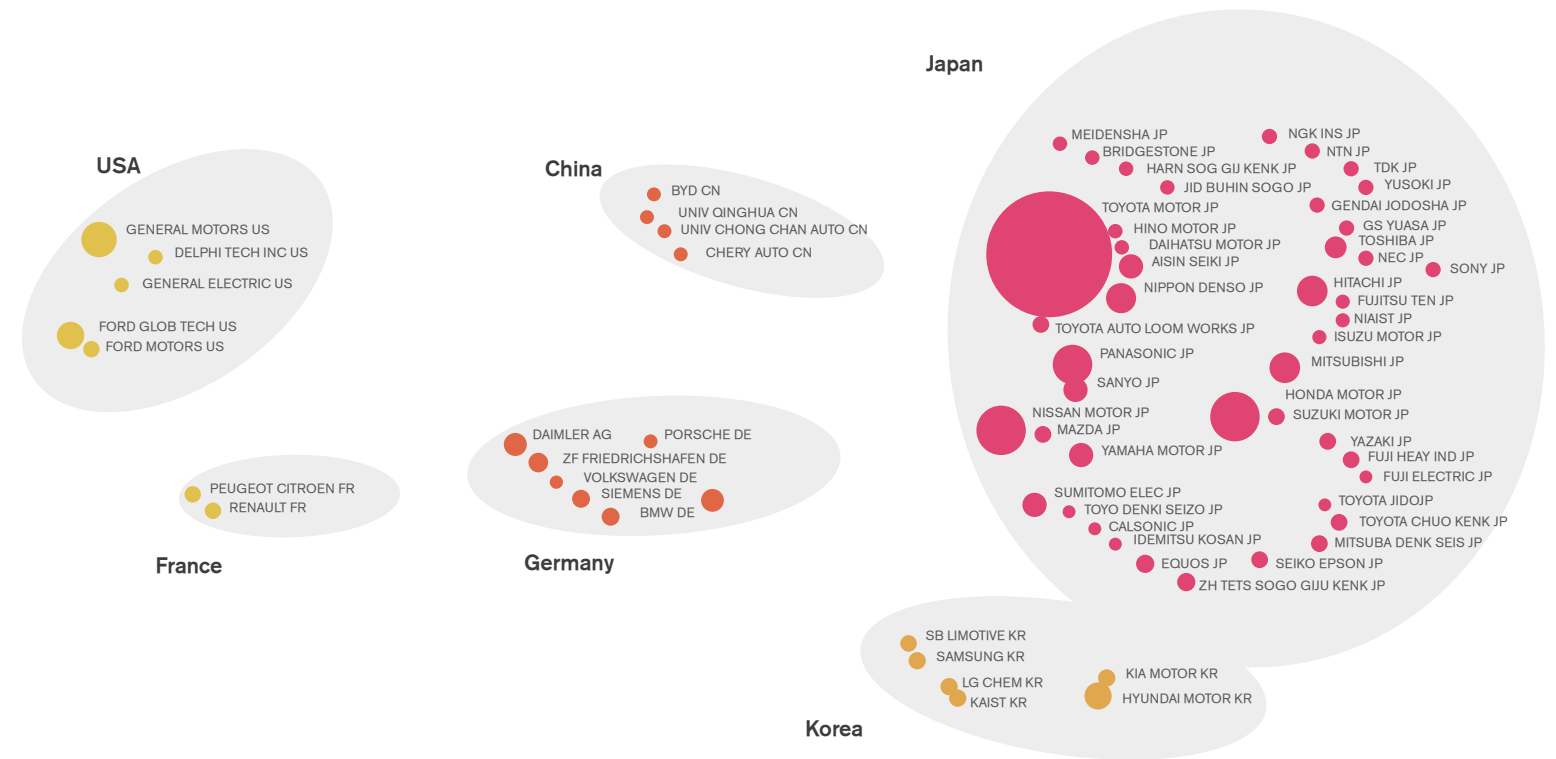

Figure 15.3 Electric and hybrid electric vehicle patents per institution (Only organisations with at least 100 patents from 1963-2012 are included).

The extent to which R\&D data can reveal technological leadership in the electrification field is debatable. Whilst Japanese companies are market leaders in the market for HEVs, for instance, there is evidence to suggest that automakers such as Toyota pursue different strategies to US-based companies such as GM as regards accessing technologies that are key to electrification such as batteries. Japanese firms focus more on developing technologies internally whereas US firms tend to work with a broader range of suppliers to access the key technologies such as batteries.?

The main implication is that automakers can utilise external sources of knowledge and competences related to key components in order to develop electrified vehicles. Furthermore, automakers initially prefer to focus on architectural (as opposed to component) knowledge and competences as a means to offset the risks and uncertainties associated with paradigmatic technological change. ${ }^{8}$ One such risk is that leadership in a rapidly evolving technological field is difficult to maintain, since technologies develop quickly and since electric vehicles are competing with other alternative vehicle technologies. It may be the case that many of the patented technologies shown in Table 15.1 are no longer that 'significant'. R\&D collaboration is a means to offset this type of risk. It is thus relevant to consider the ways in which automakers collaborate and the conditions that support collaborative R\&D.

7 Pohl, H. And Yarime, M. (2010). Relations between battery suppliers and automakers for knowledge base development during paradigmatic shifts in technology. Paper presented at the Organization Learning, Knowledge and Capabilities Conference 2010, University of Warwivk, UK.

8 lbid. 
Table 15.1 'Significant' patent ownership in the field of electrification. ${ }^{9}$

\begin{tabular}{|c|c|}
\hline Assignee Company & Number of patents held \\
\hline Toyota Jidosha Kabushiki Kaisha & 24 \\
\hline General Electric Company & 14 \\
\hline Mitsubishi Jidosha Kogyo KK & 5 \\
\hline Ford Motor Company & 4 \\
\hline Nippondenso Co., Ltd. & 4 \\
\hline Nissan Motor Co., Ltd. & 4 \\
\hline Aisin Aw Co., Ltd. & 3 \\
\hline Daimler-Benz AG Chrysler & 3 \\
\hline Fuji Electric Co., Ltd. & 3 \\
\hline General Motors Corporation & 3 \\
\hline Honda Giken Kogyo Kabushiki Kaisha & 3 \\
\hline Lucas Industries Limited & 3 \\
\hline Newport News Shipbuilding and Dry Dock Company & 3 \\
\hline USA Government & 3 \\
\hline
\end{tabular}

\section{FORMS OF R\&D COLLABORATION}

Scholars have known about the importance of interaction and collaboration for innovation for a long time. Over a century ago, Alfred Marshall argued that innovation is a collective act having noted that internal processes within firms account for only a fraction of their development. ${ }^{10}$ In recent decades, scholars have increasingly recognised that firms are dependent on regional clusters and innovation systems, where a range of actors develop knowledge, competence, infrastructure, regulation, norms and markets collectively. This chapter focuses on the knowledge dimension of innovation systems. The systemic, or 'open', nature of innovation means that firms may find it useful to collaborate with rival firms, suppliers, customers, universities and research institutes that can assist in generating ideas and knowledge for new innovations. ${ }^{11}$

\footnotetext{
9 Pilkington, A. Dyerson, R. and Tissier, O. (2002). The electric vehicle: Patent data as indicators of technological development. World Patent Information Vol. 24 No. 1, pp. 5-12.

10 Marshall, A. (1890). Principles of Economics. (First Edition). London: Macmillan.

11 Gilsing, V., Nooteboom, B., Vanhaverbeke, W., Duysters, G., and van den Oord, A. (2008). Network embeddedness and the exploration of novel technologies: Technological distance, betweenness centrality and density. Research Policy, Vol. 37 No. 10 pp. 1717-1731. Christensen, J.F. (2006). Whither core competency for the large corporation in an open innovation world? Chapter 3 in H. Chesbrough, W. Vanhaverbeke and J. West (eds.) Open Innovation: Researching a new paradigm. Oxford University Press: Oxford UK. Chesbrough, H. (2006). Open innovation: A new paradigm for understanding industrial innovation. Chapter 1 in H. Chesbrough, W. Vanhaverbeke and J. West (eds.) Open Innovation: Researching a new paradigm. Oxford University Press: Oxford UK. Langlois, R.N. (2003). The vanishing hand: the changing dynamics of industrial capitalism. Industrial and Corporate Change, Vol. 12 No. 2, pp. 351-385. Sturgeon, T.J. (2002). Modular production networks: a new American model of industrial organization. Industrial and Corporate Change, Vol. 11 No. 3, pp. 451-496.
} 
Collaboration is important because it facilitates technology transfer and allows firms to access partners' technologies and competences..$^{12}$ In other words, collaborations between two firms can help them swap knowledge and skills whilst innovating together. Firms also pursue collaborations in order to reduce or share the costs and risks of R\&D activities. ${ }^{13}$ Furthermore, given the increasing complexity of technology, firms find it difficult to maintain all of the knowledge and skills required for innovation. Collaboration allows firms to access interdisciplinary sources of knowledge and monitor developments in different technological

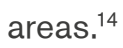

R\&D collaboration and knowledge acquisition can be organised in different ways. A general categorisation of organisational types that is useful for this particular study distinguishes between hierarchies, markets and networks. ${ }^{15}$

Hierarchical organisation could imply that firms develop new knowledge within their own organisation, but it could also involve acquisition of other companies or joint ventures and formalised strategic alliances. Compared to markets, hierarchical organisation is suited to situations with high uncertainties and risks. An example of such a risk is knowledge spillover - the process whereby actors that do not sponsor R\&D activities nonetheless benefit from gains in knowledge or competence. In such situations it is beneficial for firms to internalise R\&D activities and where necessary protect themselves from knowledge spillovers via bureaucratic means (e.g. the use of confidentiality agreements).

An alternative to internal, or internalised, R\&D is to buy knowledge and innovations on a market. Markets are suited to actors that can make exchanges with low uncertainties and risks. Market relations are typically arm's length and made on a contractual basis. Licences present one option to buy knowledge and modularisation opens a complementary pathway. A passenger car contains thousands of components that are designed and manufactured in a complex tiered system of suppliers. Modularisation means that automakers outsource the responsibility for designing key components and subsystems to suppliers. One of the main advantages of modularisation is that automakers can utilise value chain competences to boost their own competitive advantage. ${ }^{16}$

\footnotetext{
12 Lynn, L. H. (1988). Multinational joint ventures in the steel industry. In D. C. Mowery (ed.), International Collaborative Ventures in U.S. Manufacturing. Ballinger. Cambridge, MA. Mariti, P. and R. H. Smiley (1983). Co-operative agreements and the organization of industry. Journal of Industrial Economics, Vol. 31, pp. 437-451.

13 Mowery, D. C. (1988). Joint ventures in the U.S. commercial aircraft industry. In D. C. Mowery (ed.), International Collaborative Ventures in U.S. Manufacturing. Ballinger, Cambridge, MA. Mytelka, L. and M. Delapierre (1987). The alliance strategies of European firms in the information technology industry and the role of Esprit. Journal of Common Market Studies, Vol. 26, pp. 231-253. 14 Porter, M. E. and Fuller, M. B. (1986). Coalitions and global strategies. In M. E. Porter (ed.), Competition in Global Industries. Harvard Business School Press, Boston, MA, pp. 315-344. Hagedoorn, J. and Schakenraad, J. (1990). Inter-firm partnerships and cooperative strategies in core technologies. In C. Freeman and L. Soete (eds.), New Explorations in the Economics of Technical Change. Pinter, London, pp. 3-37.

15 Powell, W.W. (1990). Neither market nor hierarchy: Network forms of organization. Research in Organizational Behavior, Vol. 12, pp. 295-336.

16 Howard, M. and Squire, B. (2007). Modularization and the impact on supply relationships. International Journal of Operations \& Production Management, Vol. 27 No. 11, pp. 1192-1212. Morris, D. and Donnelly, T. (2006). Are there market limits to modularisation?. International Journal of Automotive Technology and Management, Vol. 6 No. 3, pp. 262-275.
} 
Although R\&D activities are outsourced to suppliers, automakers must retain some level of competence regarding these activities or risk their competitive advantage. Automakers thus face a significant challenge in that they must develop and maintain technical competences that complement those in the value chain. ${ }^{17}$ Automakers also face the risk that key competences are made available to competitors via shared suppliers.

Networks are more relational and trust-based than markets and hierarchies, and actors collaborate in networks due to mutual benefits and complementary strengths. Networks are suitable when uncertainty about performance, costs and value is very large, making market arrangements, as well as costly and bureaucratic hierarchal organisations, less attractive.

There are various known barriers to collaboration in networks. First, firms seeking to collaborate in order to access technology must know that the technology exists, which is a challenge given the complexities of global markets. Alternatively, individuals within firms may be aware of such opportunities but lack personal contacts with relevant individuals in partner organisations. In other words, whilst workers may boast a lot of know-how, they may not have the necessary know-who to facilitate effective collaboration. Know-who means that individuals' social networks can be important for collaboration. ${ }^{18}$

Second, opportunities to collaborate via networks may be constrained by the system of intellectual property rights (IPR). Whilst patents, for instance, create incentives to innovate, the patenting system creates incentives to trade inventive knowledge in a competitive market setting rather than via more open systems of collaboration. ${ }^{19}$

Third, opportunities for collaboration may be constrained by the types of knowledge that is to be shared between actors. A distinction can be made between tacit and codified knowledge (Polanyi, 1967). Tacit knowledge refers to competences and skills that are hard to codify with the result that knowledge transfer requires face-to-face collaboration. In contrast, codified knowledge can be exchanged more freely between individuals without interpersonal contact. Some scholars have argued that these features influence the geography of innovation in that industries operating primarily on tacit knowledge pursue collaborations on a more localised scale. ${ }^{20}$ Other factors that reinforce the importance of the local scale include the costs of collaboration over longer distances, language and cultural/ institutional differences. ${ }^{21}$

17 Takeishi, A. (2002). Knowledge Partitioning in the Interfirm Division of Labor: The Case of Automotive Product Development. Organization Science, Vol. 13 No.3, pp. 321-338. Morris, D. and Donnelly, T. (2006). Are there market limits to modularisation?. International Journal of Automotive Technology and Management, Vol. 6 No. 3, pp. 262-275.

18 Lundvall B.A. and Johnson, B. (1994). The learning economy. Journal of Industry Studies, Vol. 1 No. 2, pp. $23-42$.

19 Hall, B.P. (2007). Patents and Patent Policy. Oxford Review of Economic Policy, Vol. 23 No. 4, pp. 568-587. Hall, B.P. and Hellmers, C. (2010). The role of patent protection in (clean/green) technology tranfser. Santa Clara High Technology Law Journal, Vol. 26, pp. 487-532

20 Martin, R., and Moodysson, J. (2011). Comparing knowledge bases: on the geography and organization of knowledge sourcing in the regional innovation system of Scania, Sweden. European Planning Studies, Vol. 19 No. 7, pp. 1183-1203.

21 Tidd,J., Bessant,J. and Pavitt,K. (2005). Managing Innovation: Integrating Technological, Market and Organizational Change, Hoboken: Wiley (3rd edition). 


\section{AUTOMAKERS' R\&D COLLABORATIONS}

The following figures map automakers' R\&D collaborations. The maps are generated from bibliometric data (co-authorship) and patent data (co-invention). Generally, bibliometric data show that whilst automakers are capable of establishing collaborations with different types of organisations across the globe, they collaborate mainly with organisations that are located in the same country as their own headquarters. Furthermore, a pattern can be observed in data on publications where automakers have the strongest ties with a single organisation, usually a university, technical college or polytechnic that is located close to the firms' main development or manufacturing operations. This is shown in Figure 15.4. Volvo Cars' main partner is Chalmers University of Technology. Like Volvo, Chalmers is located in Gothenburg, Sweden and collaborations between the two account for $25 \%$ of the 288 publications accessed for Volvo Cars.

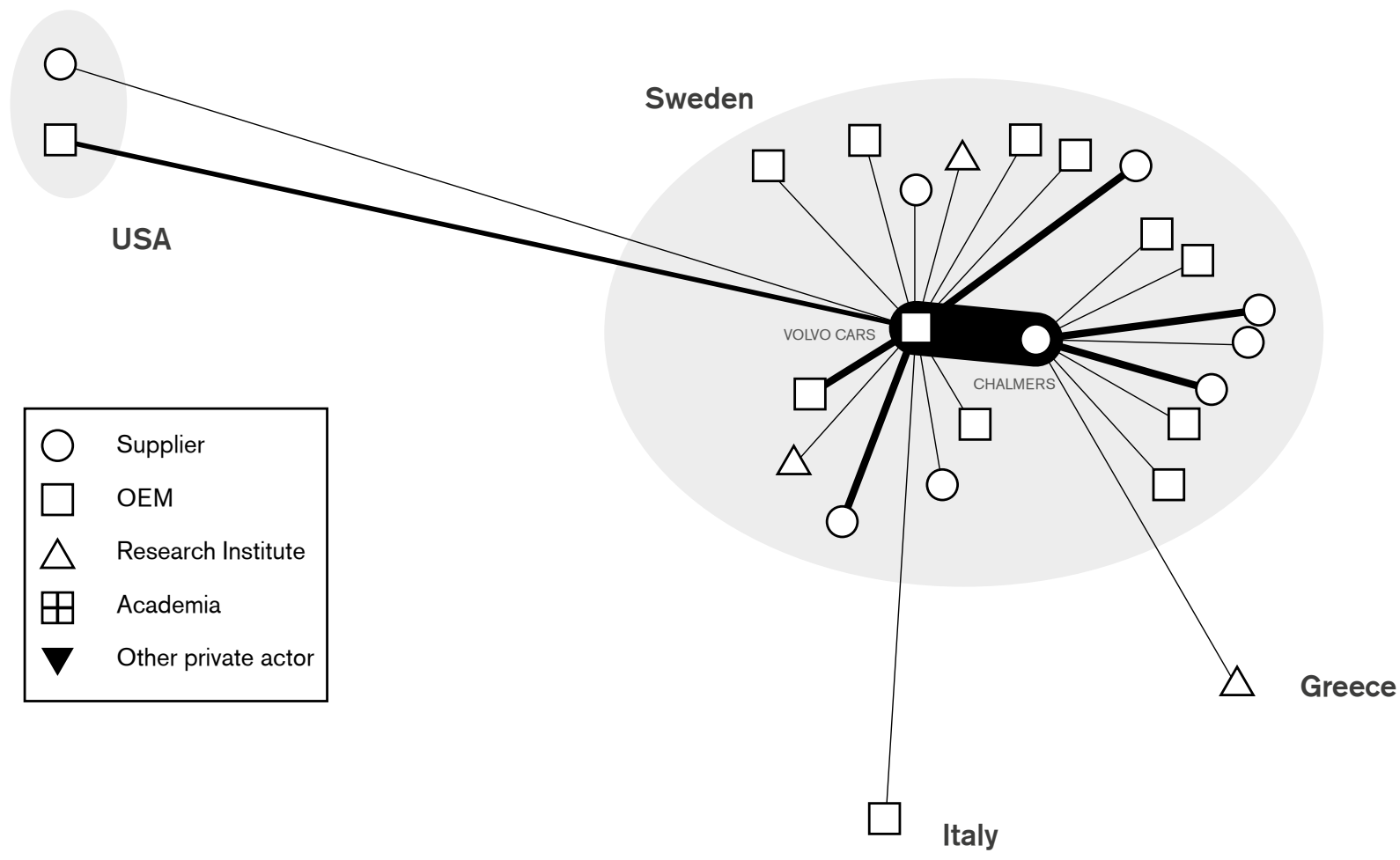

Figure 15.4 Bibliometric network data for Volvo Cars.

This pattern, whereby an automaker demonstrates strong ties with a local academic partner, was observed for each of the automakers that featured in the study (including Ford, FIAT, Hino, Renault, Scania and Volkswagen). Overall, publications records also show that automakers collaborate mainly within national borders, although several collaborations exist with foreign partners (Table 15.2). Furthermore, and as expected, automakers collaborate mainly on publications with academic partners. 
Table 15.2 Geography and diversity of partners for collaboration in the automotive industry (bibliometric data collected between 1899-2012). 'Local' partners are those within national borders; 'regional' partners are from the same continent; and 'global' partners are from a different continent than the automaker in question.

\begin{tabular}{lccccccc} 
& \multicolumn{1}{c}{ Geography of collaboration } & \multicolumn{3}{c}{ Type of partner } \\
\hline & Local & Regional & Global & Academia & Corporate & $\begin{array}{c}\text { Research } \\
\text { institute }\end{array}$ & $\begin{array}{c}\text { Gov't/ } \\
\text { NGO/other }\end{array}$ \\
\hline FIAT & 253 & 240 & 46 & 297 & 104 & 79 & 59 \\
\hline Ford & 2453 & 113 & 717 & 2662 & 260 & 191 & 154 \\
\hline Hino & 31 & 0 & 1 & 12 & 12 & 10 & 9 \\
\hline Renault & 472 & 33 & 13 & 313 & 47 & 156 & 2 \\
\hline Scania & 100 & 9 & 8 & 96 & 16 & 1 & 4 \\
\hline Volkswagen & 266 & 67 & 25 & 184 & 94 & 71 & 4 \\
\hline Volvo Cars & 187 & 4 & 7 & 152 & 38 & 8 & 0 \\
\hline Total & $\mathbf{3 7 4 4}$ & $\mathbf{4 6 6}$ & $\mathbf{8 1 7}$ & $\mathbf{3 7 1 6}$ & $\mathbf{5 6 9}$ & $\mathbf{5 1 5}$ & $\mathbf{2 2 8}$ \\
Percentage & $\mathbf{7 5} \%$ & $\mathbf{9} \%$ & $\mathbf{1 6} \%$ & $\mathbf{7 4 \%}$ & $\mathbf{1 1} \%$ & $\mathbf{1 0} \%$ & $\mathbf{5} \%$
\end{tabular}

Patent data shows that whilst local factors appear to influence R\&D collaborations, automakers are also capable of collaborating across borders, mainly via organisational hierarchies. For instance, patent data for Renault shows that its main collaborations are within France, with 5.3\% of its 11,000 patented inventions developed in collaboration with Peugeot. The two companies have a history of collaboration having developed various engines together. However, Renault has also collaborated significantly with its subsidiary, Renault Trucks (now owned by Volvo $-4.4 \%$ of patents) and more recently with its subsidiary Renault Samsung Motors, which is located in South Korea (Figure 15.5). These also represent organisational hierarchies, the latter being an example of cross-border collaboration.

FIAT's (Figure 15.6) main partner for patents is Centro Richerche FIAT (the FIAT research centre $-5 \%$ of 2500 patented inventions), which serves "as a centre of expertise for the [FIAT] Group's innovation and development activities". ${ }^{22}$ The centre is located in Turin, which reinforces the importance of the local scale. FIAT Automobiles has also collaborated significantly with Alfa Lancia (2\%) and Bosch (1.5\%). Alfa Lancia was purchased by the FIAT Group in $1986,{ }^{23}$ with headquarters also located in Turin. Bosch, however, is located in Germany and has served as a significant supplier to FIAT having provided its popular start-stop system for the FIAT 500, for instance. ${ }^{24}$

22 FIAT S.p.A - Centro Ricerche Fiat. Accessed on October 4, 2012. The centre is treated here as an external organisation since it serves the entire FIAT Group, not just FIAT automobiles.

23 Alfa Lancia was split into two separate subsidiaries of FIAT in 2007.

24 The start-stop system prevents engine idling when vehicles are not in motion - a significant feature for some electrified vehicles. 
Taken together, these patterns of collaboration reinforce the importance of the local scale, but FIAT's history of collaboration with Bosch suggests that crossborder ties can also be of significance.

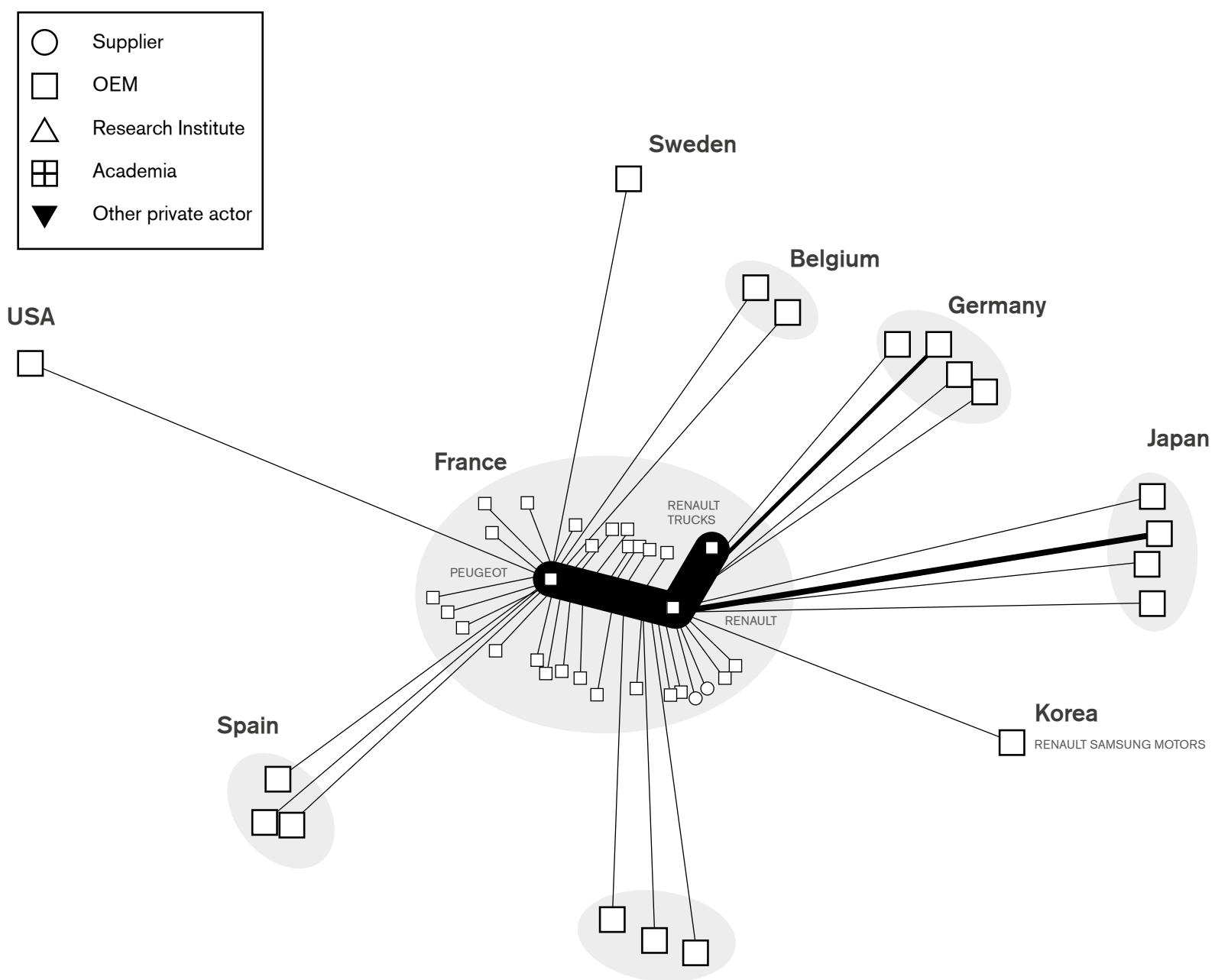

Figure 15.5 Network data for Renault (patents)

Ties with FIAT's research centre and Alfa Lancia suggest that organisational hierarchies are important for collaboration, whereas ties with Bosch are less easy to evaluate. Whilst Bosch is a significant supplier to the automotive industry, there is no evidence of a hierarchical relationship with FIAT. However it may be the case that FIAT and other automakers have engaged in network partnerships since Bosch's start-stop technology appears in vehicles manufactured by several companies. 


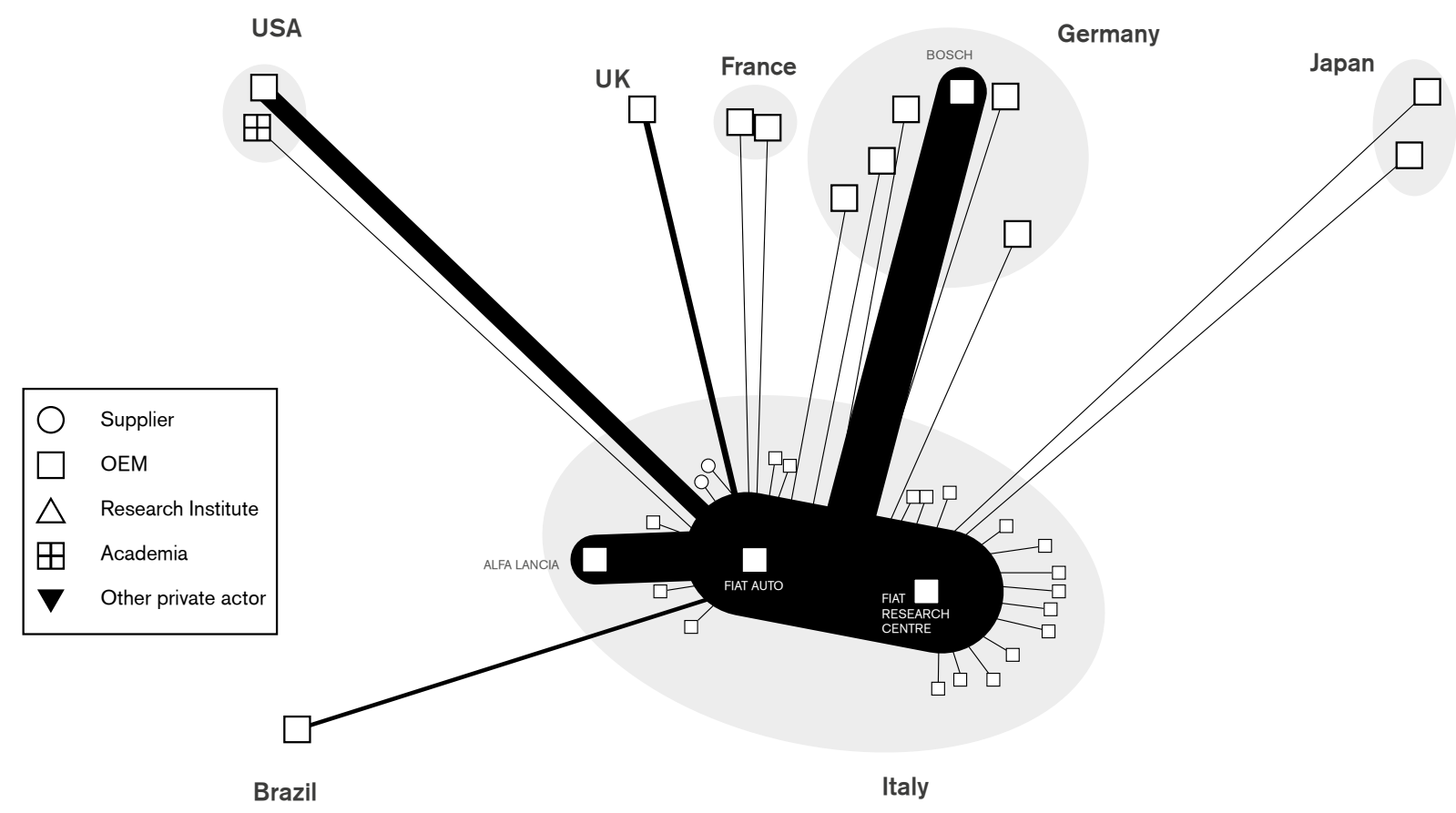

Figure 15.6 Network data for FIAT (patents)

\section{R\&D COLLABORATIONS IN THE ELECTROMOBILITY FIELD}

Since the current interest in electrification is a relatively recent phenomenon, and given that creating new knowledge networks requires considerable time, effort and resources, it is likely that automakers prefer to collaborate with established partners rather than seek out new ones based on their knowledge and competence within this field.

In the field of electrification, both bibliometric and patent data suggests that Ford prefers to collaborate with established partners. Ford's main partners in terms of publications are the University of Michigan (6.3\% of 79 publications) and Wayne State University (3.8\%). Whilst the University of Michigan has performed a significant amount of research on electrification, Ford has traditionally collaborated with these two universities. The extent to which collaborations are singularly based on motives to access technology and skills/competences is thus questionable.

Patent data on Ford shows that it has one main partner, Daimler Motors, which is located in Germany (Figure 15.7 - 9.3\% of 1300 EV patents). Ford owned Daimler between 1989-2007, and this is likely a hierarchical tie. 


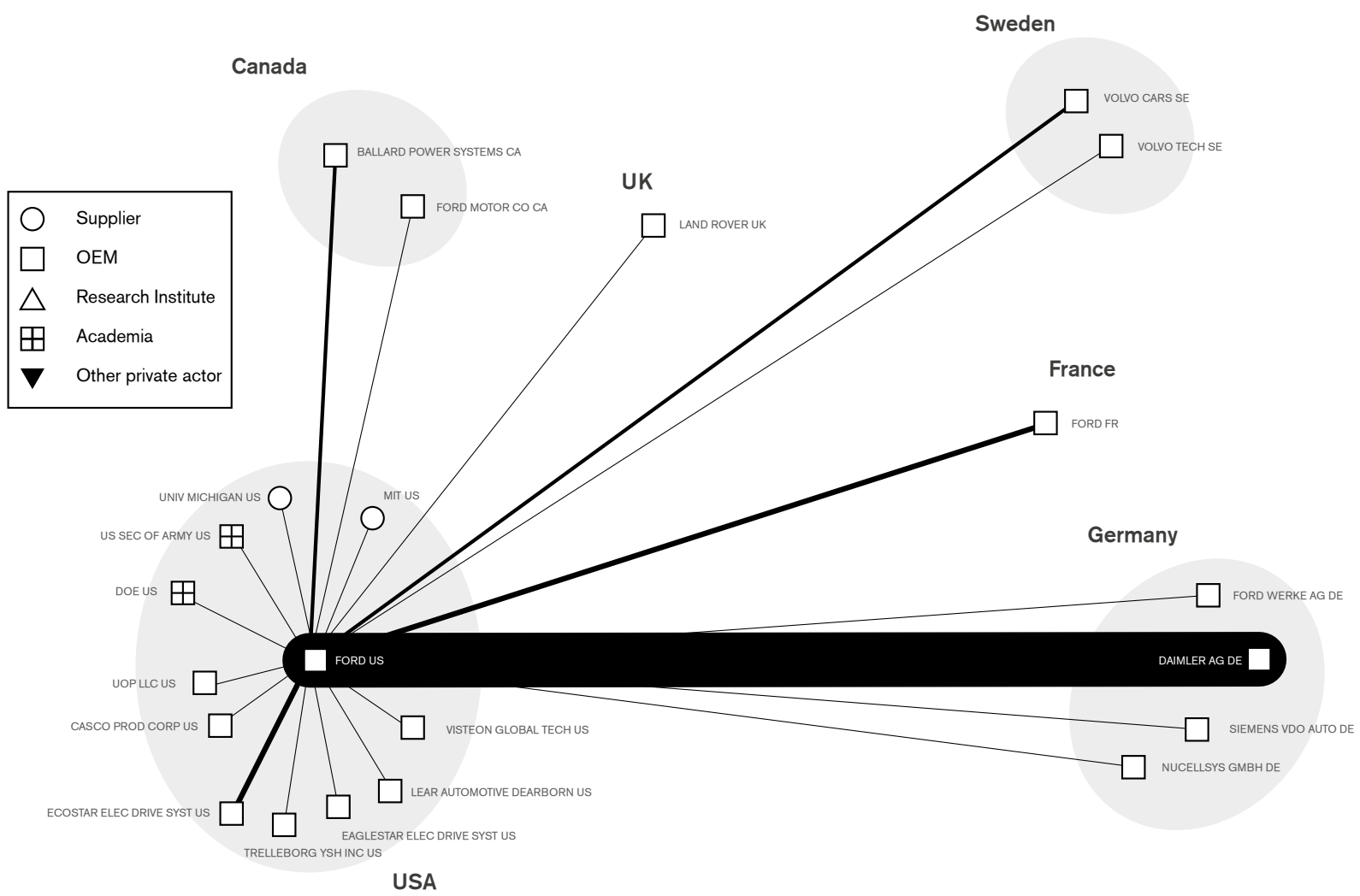

Figure 15.7 Network data for Ford (EV patents)

Similarly, FIAT has collaborated mainly with the Polytechnic University of Turin (20\% of 10 publications) and with the FIAT research centre (8.7\% of 23 patents). The latter represents a hierarchical tie, and like Ford, FIAT has a history of collaboration with these organisations. FIAT's relatively small number of electrification patents and publications suggest that it is perhaps a laggard in this field.

Patent data for Volvo Cars (Figure 15.8) add further credence to the observation that companies prefer established partners within the field of electrification and that hierarchical ties underpin patenting activities. Volvo Cars, which has only 9 patents in this field, has collaborated with the two former owners, the Volvo Group (22\% of 9 patents) and Ford (56\%).

\begin{tabular}{|ll|}
\hline$\bigcirc$ & Supplier \\
$\square$ & OEM \\
$\triangle$ & Research Institute \\
$\boxplus$ & Academia \\
$\nabla$ & Other private actor \\
\hline
\end{tabular}

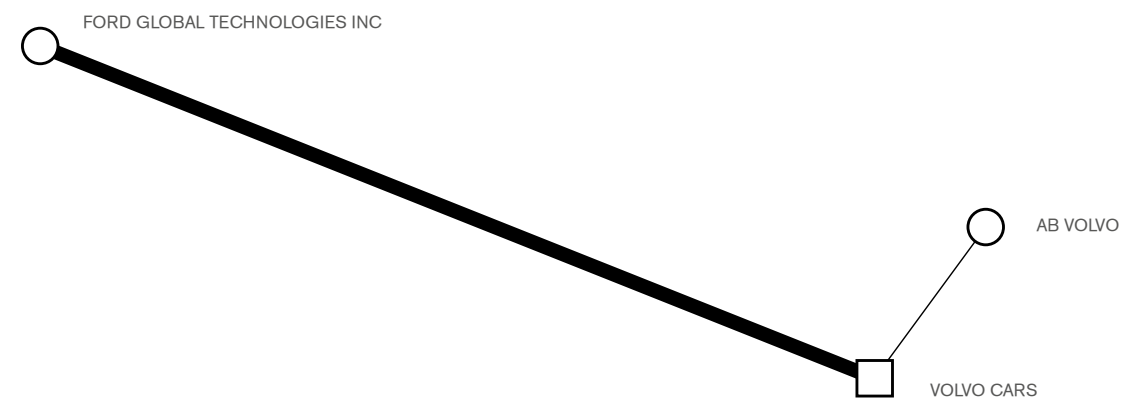

Figure 15.8 Network data for Volvo Cars (EV patents) 
Similar patterns can be found elsewhere. Volkswagen's main partner in terms of electrification publications is the University of Leibniz (19\% of 21 publications), with whom Volkswagen has collaborated historically. In terms of electrification patents, Volkswagen's main partner is its subsidiary Skoda, located in the Czech Republic (8.7\% of 263 patents), again reflecting the importance of hierarchical relationships for patented inventions.

Taken together, the data on collaborations within the field of electrification suggest that 1) automakers collaborate within established networks with academic partners; 2) automakers tend to enter collaborative relationships with private companies via existing hierarchical organisations; and 3) automakers occasionally establish ties with suppliers with competences in the field of electrification. The latter is the only real evidence of an access-to-technology driven strategy whereby automakers seek partners with competences that are of benefit in the field of electrification. The prospects for European automakers in the field of electrification may thus hinge partially on the development of knowledge and competences in Europe, given the apparent importance of collaborations with local partners. It may also depend on suppliers' abilities to collaborate with leading electrification hubs on a more global level.

\section{SUPPLY CHAIN R\&D COLLABORATIONS}

This section examines collaborative trends associated with two major European suppliers, Bosch and Siemens, that boast competences in the field of electrification and which could potentially facilitate knowledge transfers from foreign locations. Both Bosch and Siemens are headquartered in Germany, where the bulk of their operations are also located. However both companies have subsidiaries in Japan and the US, which could potentially help in facilitating the transfer of valuable knowledge and competence in the field of electromobility. Bosch has 888 patents in the field of electrification and Siemens has 374. Figure 15.9 shows that Bosch collaborates mainly with a subsidiary, SB LiMotive, which is located in Germany and Korea, and which was a joint venture between Bosch and Samsung. This again suggests that hierarchies facilitate cross-border collaboration. Furthermore, Bosch's subsidiary in Japan is key to collaborations with the Nippon Electric Works and Bosch's subsidiary in the US means that collaborations span three continents. Collaborations with automakers are relatively weak, as Bosch has patent ties with only two automakers, both located in Germany. 


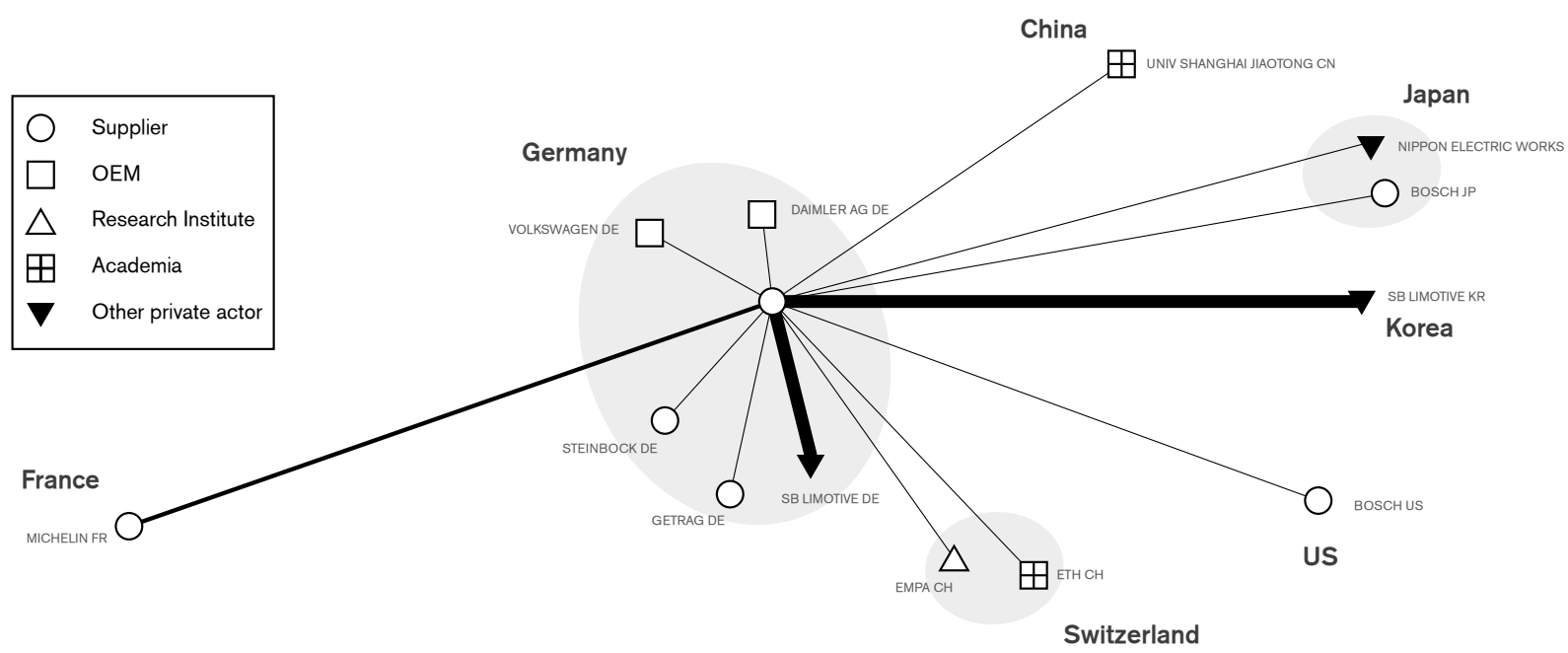

Figure 15.9 Network data for Bosch (EV patents)

Despite the fact that Siemens has fewer patents in the field of electromobil-

ity, Figure 15.10 suggests that it is embedded in a more complex collaborative network. Again, ties with the US and Japan are mainly due to the fact that Siemens has subsidiaries in these locations. And again, foreign collaboration appears to be facilitated by hierarchies. Siemens does however boast strong ties with two other suppliers within Germany (Continental and Emitec). Whether these are also due to hierarchies is unclear. Note that Siemens has only one patent collaboration with an automaker, Ford, via it's subsidiary in the US.

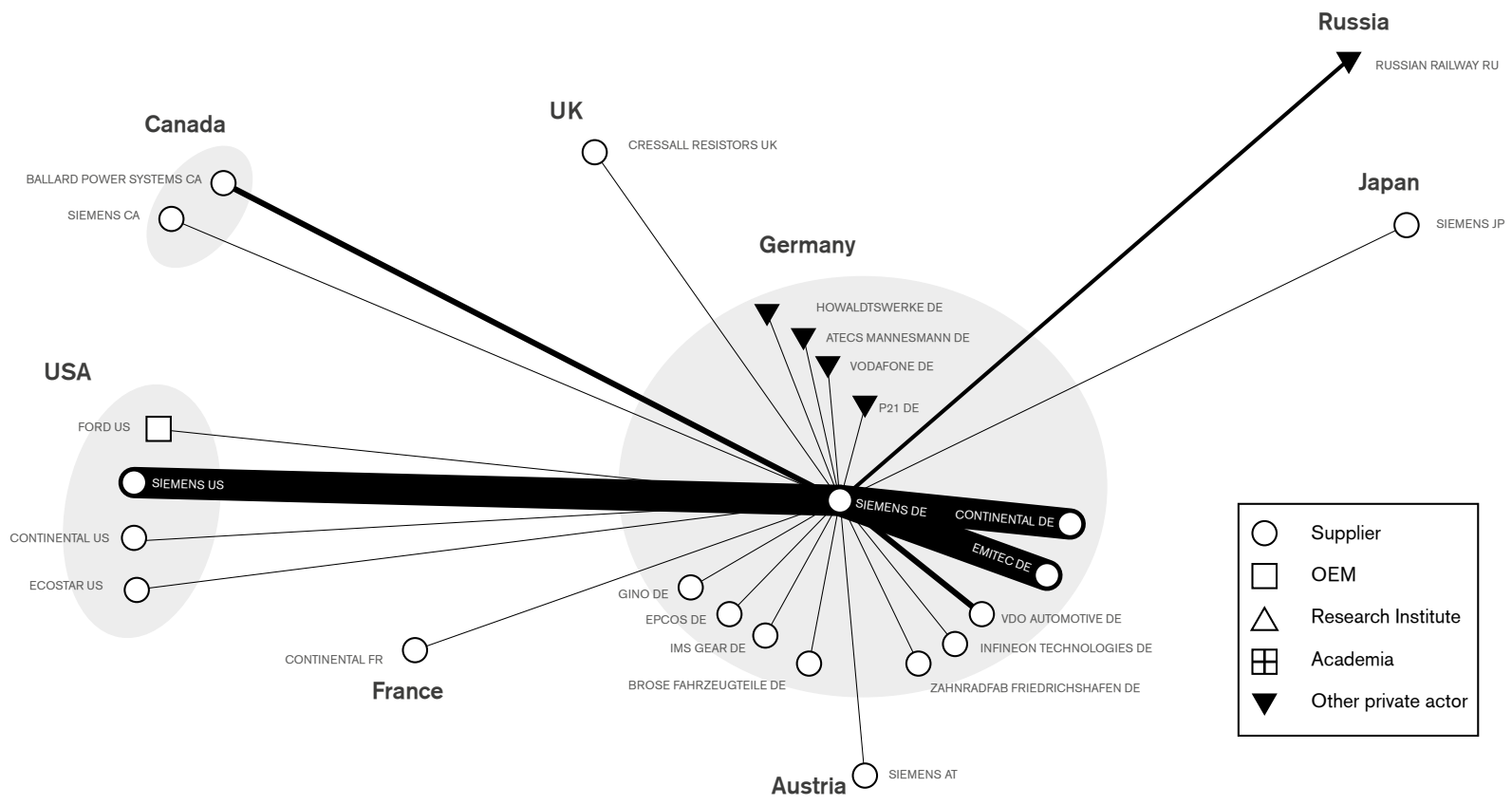

Figure 15.10 Network data for Siemens (EV patents). 


\section{CONCLUSIONS}

A number of tentative conclusions can be drawn from the bibliometric and patent data examined in this chapter. First, as regards publications, automakers tend to collaborate with academic partners that are geographically close their main operational hubs. It may be the case that academia acts as a supplier of skilled labour to the automotive industry, as a source of ideas and/or as a site for experimentation. Academia is perhaps even an indirect source of innovation for automakers even though this is difficult to measure using patent records. Despite the expansion of licensing practices and technology transfer offices that seek to create incentives for 1) university-based invention and 2) university-industry collaboration, there is evidence to suggest that academic researchers rely more on their personal social networks than formalised technology transfer practices for collaborations with industry. ${ }^{25}$ These types of collaboration are thus likely governed by network types of organisation, and thus take a long time to establish and change.

One implication for policymakers is that the provision of targeted and strategic funding for academic research may be of benefit for automakers in terms of competence enhancement and innovation. Here it may be beneficial to sponsor research on electrification within academic institutions that are based in the same localities as major automakers. Whilst the exact impacts of such research are unknown, some sort of positive spillover is likely given the strong ties between these two sets of actors. Furthermore, this type of policy intervention may be of paramount importance for the European automotive industry given that Japan and the US appear to be leading in the field of electrification. The provision of funding to academic institutions that have a history of collaboration with automakers is a good start and should perhaps be complemented by mechanisms that stimulate knowledge transfer between European universities and their academic partners in the Japan and US. This type of policy intervention may also be key to ensuring the long-term sustainability of the automotive industry given pressures to find alternative, environment-friendly technologies and given the current economic climate where automakers find it hard to justify the costs of R\&D on alternative technologies. ${ }^{26}$

Second, patent records suggest that inventions are more likely to occur between companies that share some type of hierarchical organisational structure than between other types of organisation. This appears to be the case for both automakers and suppliers to the automotive industry. Records suggest that openly innovative network structures are not the primary structures for inventive collaborations, as most occur within existing corporate structures (i.e. with parent or subsidiary companies) or with companies that are part of a strategic alliance or joint venture. This suggests that the risks and uncertainties associated with open innovation pose a significant obstacle for collaborations.

However, and in contrast to bibliometric data, patent records do suggest that geography is not a significant barrier for collaboration. Companies are capable of establishing strong ties with foreign partners where the above conditions are

25 Siegel, D.S., Waldman, D.A., Atwater, L.E. and Link, A.N. (2003). Commercial knowledge transfers from universities to firms: Improving the effectiveness of university-industry collaboration. Journal of High Technology Management Research, Vol. 14, pp. 111-133.

26 Wells P.E. (2010). The automotive industry in an era of eco-austerity. Edward Elgar: Cheltenham UK. 
satisfied. This brings us to a third tentative conclusion. Whilst it is widely acknowledged that trust is an important precondition for efficacy in collaborations, the findings shown here suggest that trust is realised through different organisational structures. In publication networks it appears to be the case that proximity is the key to strong ties, which may be due to individuals' own social networks and the propensity for individuals within these networks to meet more often and participate in the same collegial communities. In contrast, patent collaborations appear to require different sorts of mechanisms to ensure reciprocity in that organisational hierarchies perhaps compensate for a lack of trust given the uncertainties and risks attached to cross-border collaboration.

The good news for automakers is that geography appears not to be a significant obstacle for patent collaborations. It is either the case that the knowledge that underpins inventive collaborations in the automotive industry is to a large extent codifiable and thus renders geography unimportant, or that automakers have found ways to overcome the need for proximity when collaborating on new inventions. Although organisational hierarchies appear to facilitate cross-border collaboration, the extent to which these ties represent true collaboration and not, for example, instances where parent companies appropriate patentable inventions from their subsidiaries is not clear. This is a topic for further investigation.

Notwithstanding, practitioners may benefit from establishing hierarchical agreements with companies in countries such as the US, China and Japan that appear to be at the forefront of the electrification field. The extent to which it is necessary for Swedish automakers to pursue such an approach is however unclear. It may be the case that market modes are sufficient in that Swedish automakers can simply purchase components and sub-systems such as batteries and hybridised powertrains from key suppliers as part of a modularisation strategy. However, such an approach has been noted for its risks, as by simply purchasing key technologies 'off the shelf', automakers can lose the architectural competences that are key to competitive advantage.$^{27} \mathrm{~A}$ precautionary approach would thus be to ensure that automakers retain and build competences that are relevant to electrification, which we assume will play a significant role in years to come. This further emphasises the point made above that strategic and targeted academic funding is required to match the needs of automakers in terms of competences and skilled labour, given the prevalence of local academy-industry ties. 